\title{
Pronunciation and Comprehension of Oral English in the English as a Foreign Language Class: Key Aspects, Students' Perceptions and Proposals*
}

\author{
Nuria Edo Marzá \\ English Studies Department, University Jaume I, Castellón, Spain
}

\begin{abstract}
Traditionally, little attention has been paid to learners' perceptions of pronunciation and comprehension instruction in English as a Foreign Language (EFL) contexts. This study is aimed at putting forward a series of detected key aspects, students' perceptions and proposals for enhancing, improving and implementing pronunciation and comprehension skills in the Spanish higher-education EFL class -specifically a pronunciation class. By means of the administration to students of three questionnaires designed ad hoc for this small-scale, pilot study, a diagnostic analysis has been carried out that has yield to valuable data and to the suggestion of specific proposals derived from first-hand experience. Accordingly, among other aspects, the results obtained show that students' motivation and implication is high when being taught pronunciation, they believe in the usefulness of pronunciation instruction, but at the same time they may experiment frustration relatively easily, especially due to inhibition and peer-comparison factors that may negatively affect performance and self-confidence. In the same way, students are aware of the importance of both segmental and suprasegmental aspects in order to favor comprehensibility, they consider variation in means, methods and activities to be fundamental in the classroom in order to keep their own interest and motivation and they find computer-assisted and audio-visual aids highly useful and valued when it comes to learn pronunciation.
\end{abstract}

Index Terms-pronunciation, comprehension, questionnaire, diagnostic analysis, segmental features, suprasegmental features, EFL class

\section{INTRODUCTION}

\section{A. Background and Objectives}

It is beyond doubt that pronouncing a language properly is a key aspect when understanding and making ourselves understood. In the English as a Foreign Language (EFL) teaching and learning process pronunciation should play a determining role since it is directly related with the development of students' communicative competence and thus to language proficiency and comprehensibility.

Spoken communication is grounded on the communicability not only determined by correct grammar and profuse vocabulary but also on the correct interplay between the segmental and suprasegmental features making up pronunciation. As Burns (2003) concedes, despite minor inaccuracies in vocabulary and grammar, learners are more likely to communicate effectively when they have good pronunciation and intonation. Nowadays, as Pourhosein (2012, p.120) states, despite the "emphasis on the importance of meaningful communication and intelligible pronunciation, it is not enough to leave pronunciation teaching and training to pronunciation classes only"; it is determining that the relatively few hours devoted to this purpose in the curriculum are planned and devised to make the most of them, giving students the tools to continue improving on their own and the voice to express in which ways they learn the best. In spite of this, "researchers in applied linguistics have paid little attention to learners' perceptions of pronunciation instruction in L2 contexts" (Kang, 2010) so that this article has tried to deepen on students' perceptions and feelings about English pronunciation issues in general and about the English pronunciation subject EA0910 "Pronunciation and comprehension of oral English" in particular in order to make a diagnostic analysis of the situation which will ideally lead to an improvement in their pronunciation skills.

This small-scale but representative pilot study stems thus from my own concern as an English pronunciation teacher about the need to do some research on the traditionally assumed and clearly noticeable difficulties most Spanish students ${ }^{1}$ find in pronouncing English properly with the final aim to devise and implement feasible improvement

\footnotetext{
* This research has been carried out within the framework of the project entitled "Elaboración de Material didáctico de autoaprendizaje y refuerzo para la asignatura "EA0910 - Pronunciación y comprensión de la lengua inglesa" en base a la reflexión previa, autoevaluación y sugerencias del alumando", awarded by Universitat Jaume I (Castellón, Spain) in year 2012.

${ }^{1}$ In this case we are focusing on higher education students in a foreign language context. They are students of the English Studies degree (in their first year).
} 
measures. With this objective in mind, with a series of questionnaires designed ad hoc -and according to my own observation and experience- I have tried to determine students' perceptions, needs, demands and feelings regarding English pronunciation and comprehension and their views about the materials, instruction methods, tools and contents used and/or included in a regular English pronunciation class in an EFL high-education context. Students' specific suggestions have finally been analysed in order to be able to pose improvement proposals devised from first-hand experience. With this analysis of key aspects, perceptions and proposals, this study is aimed at becoming the first one from a series intended at better understanding why pronunciation is such a hurdle for Spanish EFL learners and how this could be solved or at least improved.

\section{B. Pronunciation: The Great Hurdle for Spanish EFL Students}

It is not a secret in the Spanish EFL teaching context that pronunciation is a great hurdle for most Spanish students who do not feel comfortable or at the same proficiency level of other European counterparts with the way they pronounce English. In fact, as Coe (1987 in Swan and Smith) states "European Spanish speakers, in particular, probably find English pronunciation harder than speakers of any other European language". Moreover, as Pourhosein (2012) concedes, limited pronunciation skills can affect learners' self-confidence by decreasing it, also restricting social interactions, and thus negatively affecting estimations of a speaker's credibility and abilities, which obviously negatively influences the EFL instruction process. In fact, as Jones (2002) states, pronunciation teaching methods should address the issues of motivation and exposure by creating awareness and stressing the importance of sound pronunciation. In this very same sense, Pourhosein (2012) lists a series of factors affecting the learning of English pronunciation among which we find: attitude, motivation, instruction and exposure to target language.

That pronunciation is a rather problematic aspect for most Spanish students is (regretably) a fact, but the reasons and solutions may be varied in nature and in effectiveness. Traditionally, most Spanish-speaking countries have tended (and still tend) to neglect the teaching of pronunciation in EFL settings, focusing instead on grammar, reading and writing skills. Already in 1994, Gilbert described pronunciation as an orphan in English programs around the world and in 2010 she still believed that "pronunciation continues to be the EFL/ESL orphan" (Gilbert, 2010, p. 1). This lack of enhancement of listening and speaking skills has originated generations of students with a manifested insecurity and a lack of proficiency in their oral capacities in English, something, which, on the other hand, is a general complaint and claim in the Spanish EFL context.

However, along with the weaknesses of a particular curricular design, native language may -positively or negativelyinfluence second or foreign language pronunciation since the speech habits of the mother tongue tend to superimpose on the speech habits of the target language (Akram and Qureshi, 2012). In this sense, Cunningham Florez (1998, p. 3), for instance, concedes that errors in aspiration, intonation, and rhythm in the target language are likely to be caused by interference or negative transfer from the first language and Odlin (1989, p. 112) goes on stating that, "there is no little doubt that native language phonetics and phonology are powerful influences on second language pronunciation". In this sense, Spanish and English phonological systems show important differences, especially as regards phoneme production, linking phenomena, intonation and stress, which may make pronunciation specially hard for Spanish speakers. For instance, Spanish does not distinguish between short and long vowels -the length of the vowel is not significant in order to distinguish words- so that Spanish speakers tend to confuse these pairs both in comprehension and in speaking. Moreover, as Case (2012) states, Spanish speakers tend to find great difficulty in recognising not rhotic versions of vowel sounds and, due to the differences in syllable patterns -Spanish is a syllable-timed language and English a stresstimed language-, Spanish speakers tend to add extra syllables or swallow sounds to match the expected/desired number of syllables, especially when it comes to final consonant clusters. Moreover, among many other aspects negatively affecting pronunciation in English, Spanish speakers tend to fail in pronouncing end consonants accurately or strong enough and tend to add unnecessary sound preffixes to words which begin with a consonant cluster on s-. To deepen on these specially problematic aspects, Shoebottom (2011) concedes that Spanish has a strong correspondence between the sound of a word and its spelling. However, English is irregular in this respect, this causing predictable problems when Spanish learners write a word they just first meet in spoken language or say a word first met in written language.

According to the difficulties mentioned above, it is essential that we as English teachers give our students the opportunity to reflect on the way they learn to pronounce and on the way they want to do so, so that with first-hand impressions we can improve the instruction of pronunciation and comprehension meaningfully, providing them with the necessary tools to do so independently and in a conscious and profitable way.

\section{The Importance of Comprehensibility in Oral English}

Pronunciation is a key aspect in the development of oral skills. Proper pronunciation is inherent to any competent speaker but this competence can (and must) be trained in any non-native speaker. The review of previous literature on the topic shows that with careful preparation and integration, pronunciation can play a significant role in supporting the learners' overall communicative skill (Pourhosein, 2012, p. 119). Nonetheless, the idea that learners should speak and sound like native speakers is not the trend nowadays, apart from being a rather unrealistic idea. In fact, it is rare that L2 adult learners achieve native-like speech patterns (Moyer, 2004; Scovel, 2000). Moreover, it is difficult to achieve native-like pronunciation in typical ESL classrooms after childhood (Kang, 2010). As Ur (1996) concedes, the aim of pronunciation is not to achieve a perfect imitation of native accent, but to get the learner to pronounce accurately 
enough to be easily and comfortably comprehensible to other speakers. In fact, as scholars such as Derwing and Munro (2005) or Goodwin (2001) argue that it is teachers' role to help ESL learners to set realistic goals for pronunciation instruction and these goals do not normally target native-like accents.

According to Burns (2003), it is far more important for speakers to be able to achieve intelligibility (the sound patterns produced by the speaker are recognisable as English) comprehensibility (the meaning of what is said can be understood by the listener) and interpretability (the purpose of what is said can be understood by the listener). Moreover, many studies from an English as a second language perspective -such as Howlader's (2010)- found that mutual intelligibility, comprehensibility and neutral accent can promote better oral communication. In fact, from the perspective of World Englishes, mutual intelligibility is a key issue for both listeners and speakers (Kang, 2010)

In order to achieve comprehesibility, both segmental - main focus in the teaching of pronunciation in former EFL approaches- and suprasegmental features must be paid attention to as the main components of good pronunciation (Fig. 1) and thus they are key aspects to be dealt with in a balanced and complementary way in the pronunciation class.

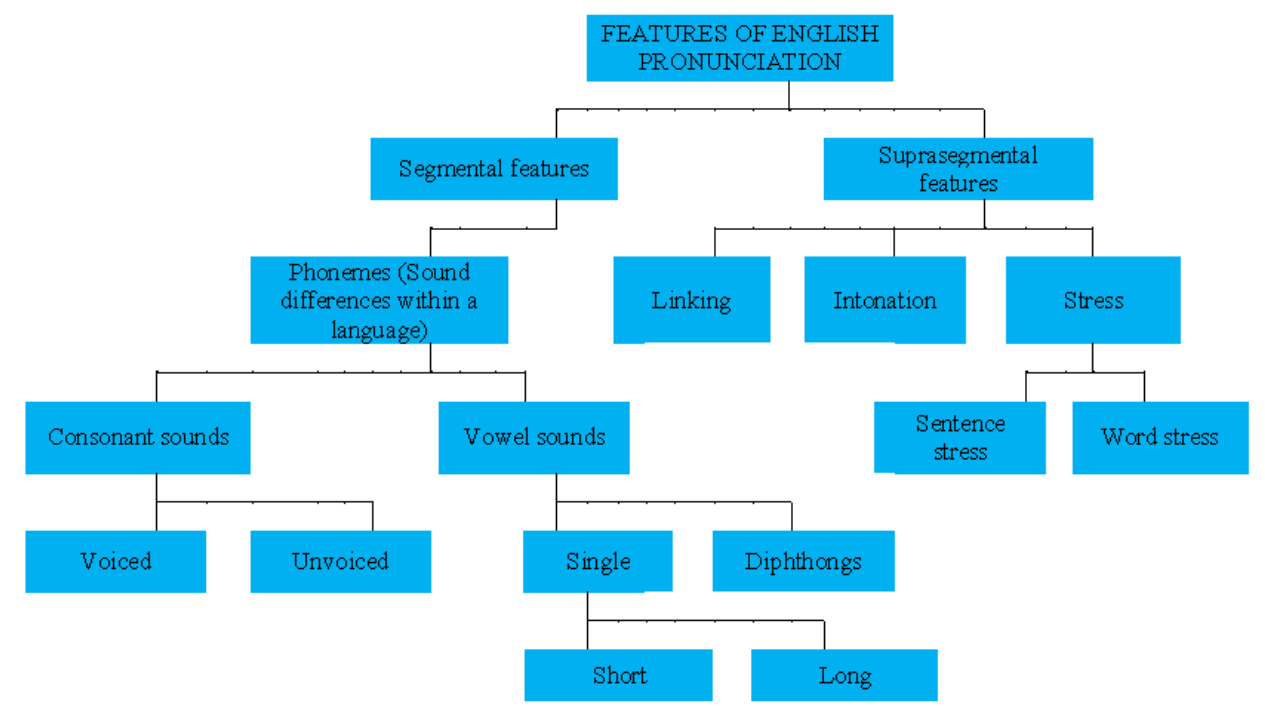

Figure 1. Features of English pronunciation according to Pourhosein (2012, p. 120).

Therefore, comprehensibility is the key nowadays due to of the increasing demand of communication in English between the non-native speakers rather than between the native and non-native ones in the world (Howlader, 2010) and accordingly it must be enhanced and trained.

\section{METHOD}

\section{A. Context for the Research}

This paper puts forward the results obtained from a small-scale pilot study about key aspects, students' perceptions and proposals to improve pronunciation and comprehension of oral English. The study population is made up of 48 Spanish students from first year of the Bachelor's Degree in English Studies and enrolled in the compulsory subject EA 0910 Spoken English: Comprehension and Pronunciation (an EFL class focused on pronunciation production and reception issues). The students belong to three different groups of practice, each of them with a different teacher but coordinated in terms of contents, methodology and assessment system. The author of this paper taught practice group number 1 (PR 1) and asked her colleagues from PR 2 and PR 3 to collaborate in the study. Therefore, from the 48 students taking part in the study, 19 belonged to PR 1, 12 to PR 2 and 17 to PR 3.

The classes took place in the language laboratory so that students had at their disposal a wide range of technical means that tried to make the practice of pronunciation more motivating and dynamic.

According to the objectives made public in the course syllabus of the subject, it focuses on the pronunciation of English in terms of producing and understanding speech sounds and its main objective is to improve the student's productive and receptive skills in the English language. More specifically, the subject deals with: segmental and suprasegmental phonology, correspondence between phonetics and spelling, discrimination of sounds in isolated words and in connected speech, and pronunciation practice in specific difficult areas for Spanish speakers. The coursebook English Pronunciation in Use - Intermediate by Mark Hancock (2012 edition) is the one used in the subject but when students take part in this second semester subject they are already familiar with the basics of pronunciation since they have already taken the subject EA0911 English Phonetics and Phonology during the first semester. This initial EA0911 course is supposed to have given the students a solid foundation in the basics of the phonological system of the English language. 
The methodology employed in this study is a simple and straightforward one: the administration via the electronic platform of the subjects' virtual classroom of 3 anonymous questionnaires (see their printed version in Appendix A) to be voluntarily responded by the students. Students were thus not forced to take part in the study but highly encouraged to do so: finally, $87 \%$ of the students enrolled in the subject took part in it.

The questionnaires were created on the basis of the aspects and phonology-related terminology which was already familiar to the students, that is, according to the main contents of the coursebook, according to personal interaction with students during tutorial hours and also according to previous similar questionnaires such as Kang's (2012), and Akram and Qureshi's (2012).

The 3 questionnaires were designed to be answered in less than 45 minutes (in total) and they dealt with different aspects which I considered to be the foundations of the research and which I grouped as follows:

Questionnaire 1 - Student's perceptions and feelings

Questionnaire 2 - Materials, methods, tools and contents employed

Questionnaire 3 - Work needed, perceived relevance and improvement suggestions

Questionnaire 1 included 25 items and questionnaire 2 included 30 items to be ranked from 1 (strongly disagree) to 5 (absolutely agree), that is, participants were asked to make scalar judgments on a five-point scale. Questionnaire 3 included a first item to rank different pronunciation-related aspects according to the work needed in them (as personally perceived by each student) from 1 (more work needed) to 8 (less work needed) and a second item in which they had to assign importance to these aspects from 1 (not at all) to 5 (a lot). Questions 3-10 in questionnaire 3 were open questions to reflect and suggest specific action so that qualitative results could be obtained. However, not all the students answered all the open questions.

The questionnaires were uploaded in the virtual classroom and those students who wanted to participate anonymously had access to them from March 15 until April 15, 2013. The questionnaires could be answered in a single session or in more than one since the answers could be saved by the system. Students were explained the mechanics of the study and its objective so that it became clear to them the importance and benefits of taking part in it. Afterwards, punctuations and means (quantitative analysis from questionnaires 1,2 and part of 3) were calculated and qualitative results and suggestions (second part of questionnaire 3) were analysed in order to obtain the results presented in section number III.

Obviously, this study may present certain limitations among which we find, for example, the limited sample under analysis -48 students took part in the study. It is not a big sample but we consider it to be big enough to obtain representative results. Additionally, it is difficult to control the interest on the part of students when responding. Due to their format, questionnaires 1 and 2 and part of questionnaire 3 may have been responded at random but the fact of having given them more than a month to answer, the fact of having made them reflect about the importance of the study and the fact that the study was voluntary seem to indicate that non-interested students simply did not participate.

\section{RESULTS}

\section{A. Questionnaires Results}

The following paragraphs summarise the results obtained in the 3 questionnaires administered to the 48 students.

\section{Questionnaire 1}

91.6\% of the students taking part in the study felt concerned about their own pronunciation (item 1) and 100\% of them considered "English comprehension and pronunciation" an important subject in their degree and felt that the subject would help them to improve their pronunciation (items 2 and 3). As regards item 4, 33.3\% of the students agree with the fact that pronunciation is a key aspect for communication and $66.6 \%$ absolutely agree with the statement. In the same way, 25\% show their agreement with the fact that English pronunciation is important for their professional future and $75 \%$ absolutely agree with it (item 5). $91.6 \%$ of the students agree or strongly agree with the fact that most of what they are taught in the subject is relevant for them (item 6) and all of them (50\% agree and 50\% strongly agree) like learning English pronunciation (item 7). 91.7\% of the students enjoy English pronunciation lessons/classes, so agrees (66.6) or absolutely agrees (25.1) with item 8 , and also a $91.7 \%$ of the students enjoy participating in games and tasks in the English pronunciation class (item 9$)$, so they agree $(41,6 \%)$ or strongly agree with the item $(50 \%)$.

In terms of the insecurity felt by students when they have to speak in English in front of their classmates (item 10) $41.6 \%$ of the students felt indecisive whereas another $41.6 \%$ agreed or strongly agreed with the fact that they feel insecure under such a circumstance. $66.6 \%$ of the students agreed or strongly agreed with the fact that they could do much better when speaking in English in front of their classmates but they feel ashamed and insecure so they deliberately avoid sounding too native-like (item 11). $100 \%$ of the learners stated (40\% agreed and $80 \%$ strongly agreed) that they wanted to be able to pronounce English just as native speakers (item 12). In fact, a $75 \%$ of the surveyed learners, conceded that it is very frustrating for them not to be able to sound as an English native (item 13). 33.3\% of the students conceded that they were not satisfied with their pronunciation in English -that is, they disagreed with the fact that they were satisfied with it, according to item 14-, 25\% felt indecisive about the statement and 41.6 did feel satisfied (33.3\% agreed and $8.3 \%$ strongly agreed).

$91.6 \%$ of the students agreed or strongly agreed with the fact that if they have a good pronunciation then they will feel more confident in English (item 15) and as regards item 16, nobody strongly agreed with the fact that pronunciation 
skills are innate, in fact $41.6 \%$ of the students felt indecisive about it and another $41.6 \%$ disagreed or strongly disagreed with the statement. $66.6 \%$ of the students agreed $(50 \%)$ or strongly agreed $(16.6 \%)$ with the fact that pronunciation skills are acquired through practice (item 17).

Item 18 shows a great variety of perspectives: $25 \%$ of the students strongly disagree with the fact that their mother tongue is a handicap for them to pronounce more correctly, $33.3 \%$ disagree, $16.6 \%$ are indecisive, and $25 \%$ agree or strongly agree with the statement. As regards item $19,66.6 \%$ of the students agreed or strongly agreed with the fact that knowing the main theoretical aspects of phonetics and phonology does not guarantee a good pronunciation (item 19) and $25 \%$ of them showed their indecision in this respect. $100 \%$ of the surveyed students felt satisfied with the effort they devote to improve their pronunciation (item 20).

In item $21,33.3 \%$ of the students agreed or strongly agreed with the fact that it is frustrating to see how some classmates have a much better pronunciation than them, and $41.6 \%$ felt indecisive about the statement; the remaining $25 \%$ disagreed or strongly disagreed. Nobody absolutely agreed with the fact that learning English was too difficult for them (item 22) and just $8.3 \%$ agreed with it whereas $58.3 \%$ disagreed with the item. As regards item 23, nobody strongly agreed with the fact that speaking is the hardest skill to develop but $50 \%$ agreed with it; $33.3 \%$ felt indecisive and $16.6 \%$ disagreed or strongly disagreed with the statement. Nobody absolutely agreed with item 24 ("I think I will never feel satisfied with my pronunciation") but $33.3 \%$ of the students agreed with it, $16.6 \%$ of them were indecisive and $50 \%$ of them disagreed or strongly disagreed with the statement. Finally, no student felt nervous in the English pronunciation class (item 25), just 33.3\% of them felt indecisive about this aspect.

Questionnaire 2

As regards the results obtained in questionnaire number $2,91.6 \%$ of the students agreed or absolutely agreed with the fact that pronunciation symbols are useful for learning pronunciation correctly (item 1). 25\% of the respondents absolutely agreed with item 2 ("I think English textbooks can help me to learn English pronunciation") and 50\% absolutely agreed with it; $16.6 \%$ disagreed with the statement and $8.3 \%$ were indecisive. Everybody supported the fact that English videos and audios can help them to learn English pronunciation (item 3), in fact, 75\% absolutely agreed and $25 \%$ agreed. $91.6 \%$ of the respondents agreed or strongly agreed with the fact that singing songs in English can improve their pronunciation (item 4) and the same percentage (91.6\%) agreed or absolutely agreed with item 5: "I think that repetition and imitation are important aspects to learn English pronunciation".

As regards item 6,50\% of the students believe (agree with the fact) that recording themselves is useful to improve their pronunciation and $33.3 \%$ of them absolutely agree with it. As regards the usefulness of printed dictionaries for learning pronunciation (item 7), 66.6\% of the students agree with their usefulness and $16.6 \%$ of them strongly agree with it while another $16.6 \%$ feel indecisive. $50 \%$ of the respondents feel dubious (indecisive) as regards item 9 ("students should be given more chances to speak in class") whereas 41.6 agree with it. $66.6 \%$ of the students agreed with the fact that attending classroom activities is useful (item 10) whereas the other $33.3 \%$ strongly agreed with it. $58.3 \%$ of the respondents absolutely agreed with the fact that the language laboratory is useful for pronunciation classes (item 11 ), $25 \%$ of them agreed and $16.6 \%$ felt indecisive.

As regards particular pronunciation-related aspects, items 12 to 30 try to measure students' attitude towards them. For these items, results have been included in the form of figures (Figs. 2, 3, 4, 5, 6, 7 and 8) to make them more visual and illustrative.
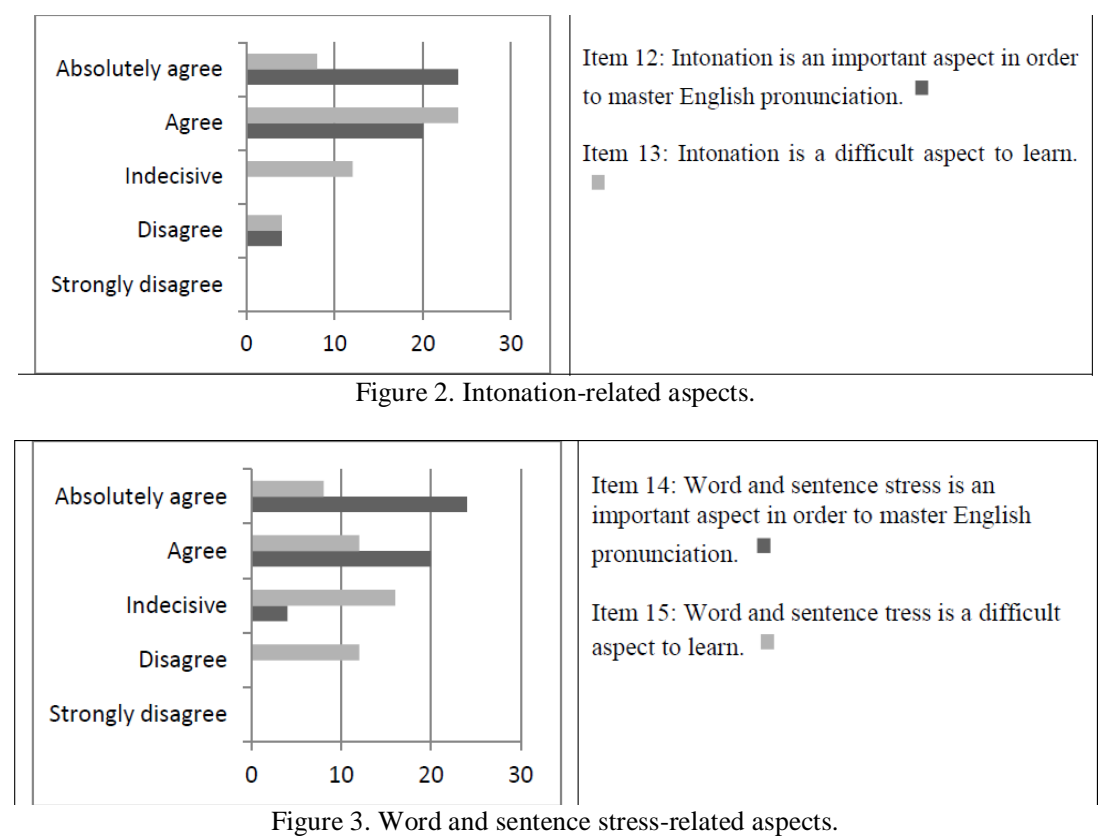


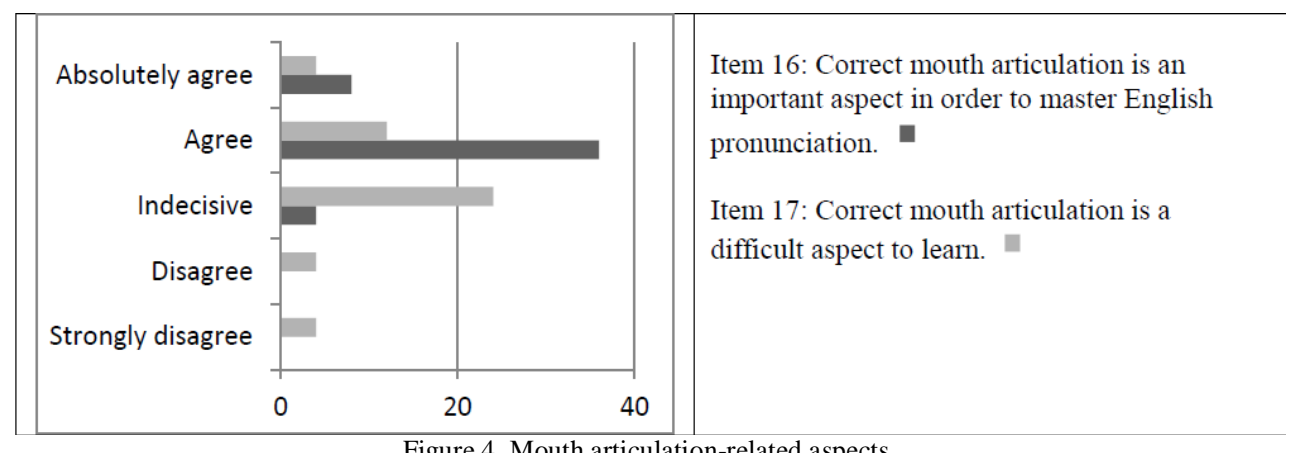

Figure 4. Mouth articulation-related aspects.

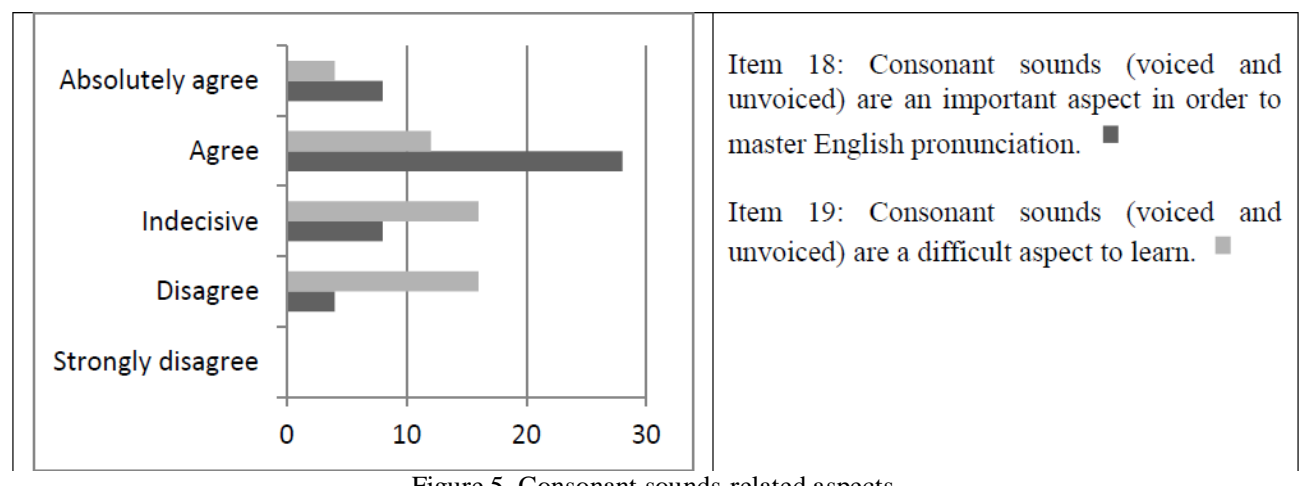

Figure 5. Consonant sounds-related aspects.

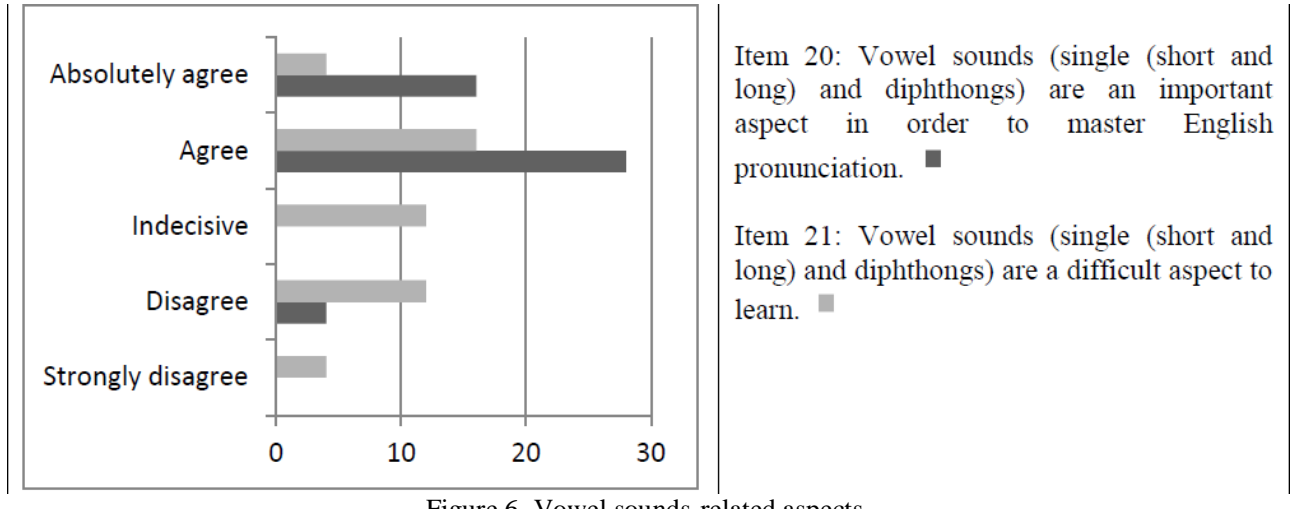

Figure 6. Vowel sounds-related aspects.

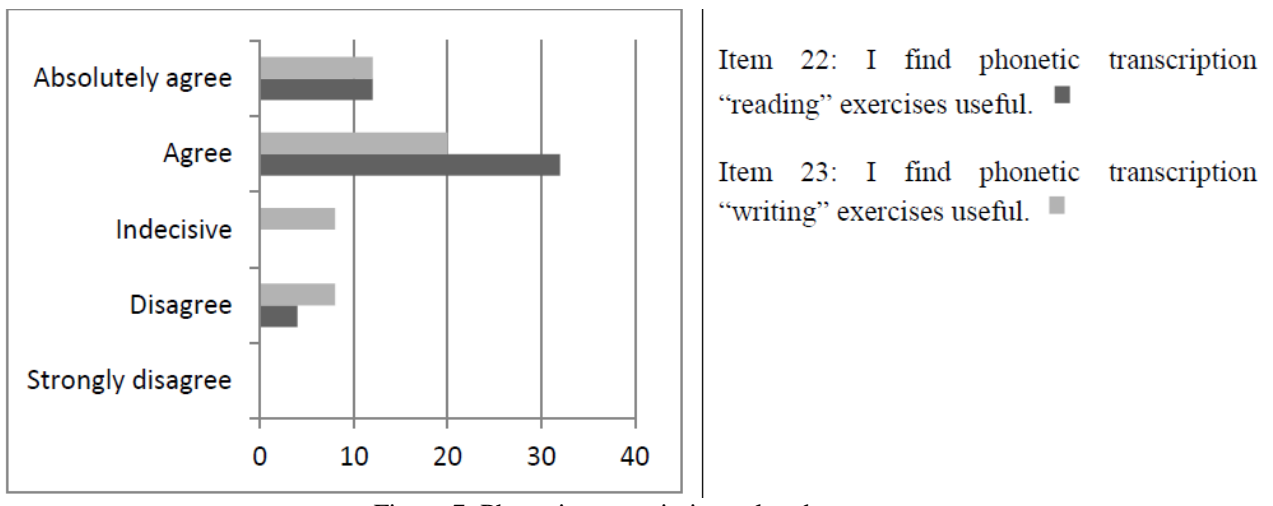

Figure 7. Phonetic transcription-related aspect. 


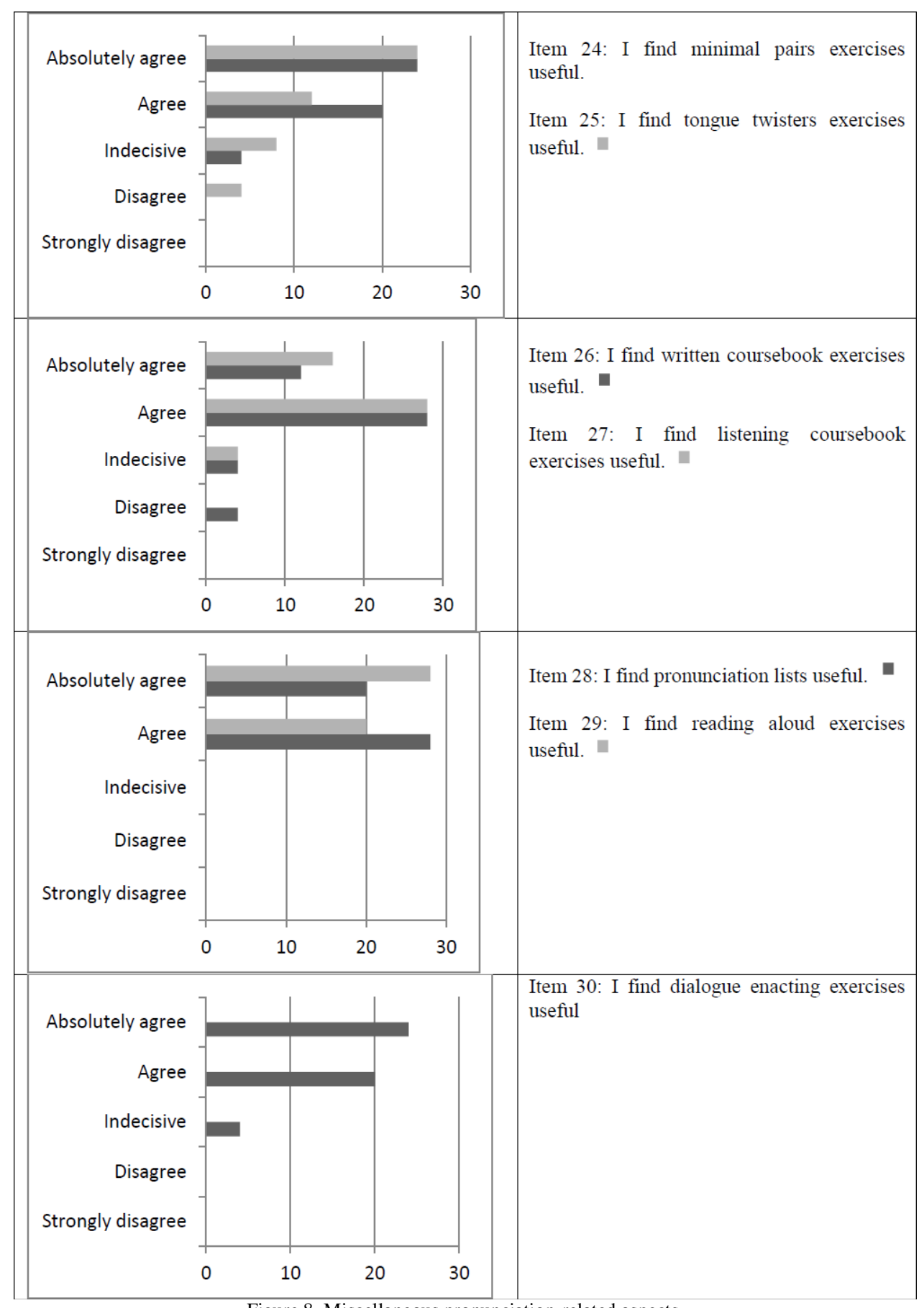

Figure 8. Miscellaneous pronunciation-related aspects.

\section{Questionnaire 3}

The results obtained in Questionnaire 3 have been summarised in the following paragraphs. Regarding the first item, in order to obtain the final rank of specific aspects student need to work on (according to their own views and perceptions) the numerical values assigned by students to each item in the ranking have been added up to a total which has been subsequently divided by the total number of students, that is, the arithmetic mean has been calculated for each item (shown between brackets) on the basis of the numerical values assigned to them. Accordingly -since 1 implies more work needed and 8 less work needed- the rank and numerical values obtained have been ( from 1 -more work needed- to 8 -less work needed-):

1 (2.1) Intonation

2 (2.5) Stress

3/4 (4.4) Vowel sounds

$3 / 4 \quad$ (4.4) Mouth articulation

5 (5.3) Phonetic transcription production

6/7 (5.6) Consonant sounds 
6/7 (5.6) Phonetic transcription reading

$8 \quad$ (6.1) Connected speech

In question 2, the arithmetic mean has been calculated in order to quantitatively rank the importance assigned by students to the different pronunciation-related aspects, punctuation ranging from 1 point (minimum -less important) to 5 points (maximum -more important). Accordingly, the assigned importance is (from 1-more important- to 8 -less important-).

1 (4.66) Intonation

2 (4.5) Connected speech

3 (4.33) Vowel sounds

$4 \quad$ (4.31) Stress

5 (4.16) Consonant sounds

6 (3.66) Mouth articulation

$7 \quad$ (3.16) Phonetic transcription reading

8 (3) Phonetic transcription production

The qualitative part of the study comprises questions 3 to 10 in Questionnaire 3. Its analysis has been more paintaking than the quantitative one but necessary in order to try to obtain relevant data regarding students' pronunciation skills, classroom activities, teachers' methodology and materials and in order to enhance students' participation according to their own perceptions and suggestions.

Regarding question number 3, that is, How would you improve classroom activities?, students' responses are closely related to what they responded in the next question (4. How would you improve students' participation?). Students point out that they would like to have more purely-speaking activities in class, that is, they emphasise the need to learn by practicing. It is also quite a repeated statement the fact that participation in class is unbalanced so people (presumably those who participate more) point out the need to try to make everybody participate in a more well-adjusted way. They also agree with the fact that fun activities, games, contests, and purely interactive activities attract their attention and motivate them more so that including more of these activities would probably enhance students' participation. Many students point out (and questionnaires reveal) that they are not much self-confident in terms of their own pronunciation so that positive reinforcement seems necessary. Many students do also point out the fact that seeing how their partners' pronunciation is better than theirs discourages them from participating so the aforementioned positive reinforcement and an adequate atmosphere play a crucial role for them.

With respect to question 5 (How would you improve teacher's methodology?), students seem to agree in the fact that it is important that teachers combine coursebook activities with other kinds of activities that may be more appealing to them. Students seem to understand the importance of the kind of practice provided by the book but they want their teacher to get actively involved in their learning by taking part in the activities themselves and by devising new ones specifically intended for the needs detected in his/her class. Closely related to their responses to question 5 are their responses to question 6 (How would you improve materials), students would add more exercises for practicing at home and ask for more recording and recorded-type activities. Some students do also believe that some of the audios provided are pretty exaggerated and thus sound a bit artificial and non-natural to them and they state they would prefer to work with more natural-sounding real pronunciation samples. In general they ask for variation and quantity so that they can focus on specific areas which may be problematic for them and find as much material as they want/need to work on them.

Regarding question number 7 (How would you particularly improve your classmates' pronunciation skills?) students seem to agree with the fact that it is very important to record oneself and then critically listen to one's own recordings. Thus, many of them do also propose some kind of peer-review correction for some of the recordings. They do also ask for a wide range of exercises at their disposal so that they can choose which aspect to study in depth. Students do also believe that the use of songs and films in English is a good, fun, and natural way to improve their listening and pronunciation skills and they do also find imitation an easy and useful activity. Reading aloud in front of the class is mentioned too and repetition is also a key issue for most of them.

Among the specific types of activities suggested for improving pronunciation (question 8), they mention again reading aloud, recording fragments, more group interaction activities, watching movies, listening to songs and audio books, getting familiar with online dictionaries and looking up any word whose pronunciation is dubious in order to check how it is pronounced, etc.

Regarding question number 9 (Why is pronunciation such a hard issue (in general) for Spanish students?) most students are aware of the fact that there are many phonological differences between English and Spanish systems and they believe this may be the origin of the problem. Some others do also point out that oral aspects in general and pronunciation in particular are not normally much dealt with in the Spanish education system. The fact of having a dubbing culture (in which original versions are hardly seen) does not help either according to many students.

Finally, as regards question 10 (Is there anything you would like to do in class (in order to improve your pronunciation) that has never been done before), some students point out that they would like to read aloud texts belonging to different genres or simply longer texts. They do also suggest the inclusion of debate-type activities and brief theatre performances which focus on the practice of the different aspects involved in pronunciation. 


\section{B. Activity-type Proposals}

According to the results obtained in the questionnaires, to my own experience in the classroom and to the feedback and suggestions obtained from students when interacting with them, a series of activity-type proposals have been developed, a selection of which I present below. Their usefulness and didactic character have been confirmed in the classroom through their implementation and they are presented here in a general way (just with a brief explanation) since they admit variation and adaptation to specific needs. They are mostly short, dynamic activities covering a wide range of pronunciation-related topics which were carried out in the pronunciation classroom together with regular coursebook activities (once questionnaire results were analysed) and which proved their usefulness and good acceptance on the part of students. Therefore, the selected activities devised and proposed are:

1. Minimal pairs: a student is provided with a numbered list of minimal pairs. A word from each pair has been highlighted and the student has to read only the highlighted word from the pair. The rest of the students note down the word read.

2. Mouthing: first the teacher (as an example) and then a student silently articulate a word by reproducing mouth position when saying the word aloud. Students have to guess the word which has been silently mouthed.

3. Sit down list: a comprehensive pronunciation list is shown to the whole class. Students stand up and each student reads aloud a word from the list. If a student fails, then he/she sits down. The last student standing up wins.

4. And the Oscar for the best imitation goes to...: the teacher selects some short movie scenes with an adequate level of difficulty and provides the students with their transcript. Students watch the scene and make notes if necessary. Then, three of the students from the class (and the teacher) will play the role of the jury and the other students will repeat the scene imitating the actor(s) or actress(es) performance. The jury will award the Oscar for the best imitation to the student who best imitates what has been seen.

5. Dialogue enacting: in groups or pairs students enact self-devised or pre-written dialogues in which different pronunciation aspects are dealt with.

6. Lyrics: firstly, the students are provided with the lyrics of a song in which some words have been removed. Students have to fill in the gaps according to what they hear and become familiar with the song. Then, they sing aloud in class imitating the singer(s).

7. Record yourself: students record themselves reading texts from different genres. Then they listen to themselves and try to record themselves again correcting the mistakes detected or improving the weak aspects. A peer-review stage can also be incorporated.

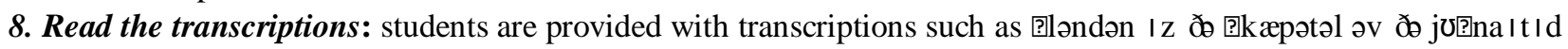

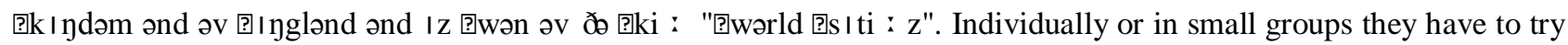
to read the transcriptions and then "decipher" them in written format.

9. Stress-full bingo: the teacher designs and distributes at random a series of pre-elaborated bingo cards with stress patterns on it (for instance, oOoo is the stress pattern for words such as particular). Then he/she reads aloud a series of words or sentences and the student with the bingo card that fits the stress patterns of the words/sentences read wins.

10. Riddle reading and recording: students read (at a different speed) a series of riddles and record themselves. They can also make up their own riddles if preferred.

11. Once upon a time...: a student stands up and the rest of the class pretends they are children listening to a great story-teller. The student starts telling a story paying much attention to intonation, stress and to the fact of catching "childrens"" interest.

12. Mirroring: students become aware of mouth articulation by slowly pronouncing a series of words from a list (proposed by the teacher or by other mates) and looking in a little mirror (they have to bring to class) the way their tongue, lips and teeth move and articulate to produce the sounds.

13. Correct punctuation can save lives: make students reflect about the importance of punctuation both when reading and writing by showing to students a series of funny examples such as the ones in Fig. 9. Students may start reading the examples aloud and then start a debate and/or look for more examples.

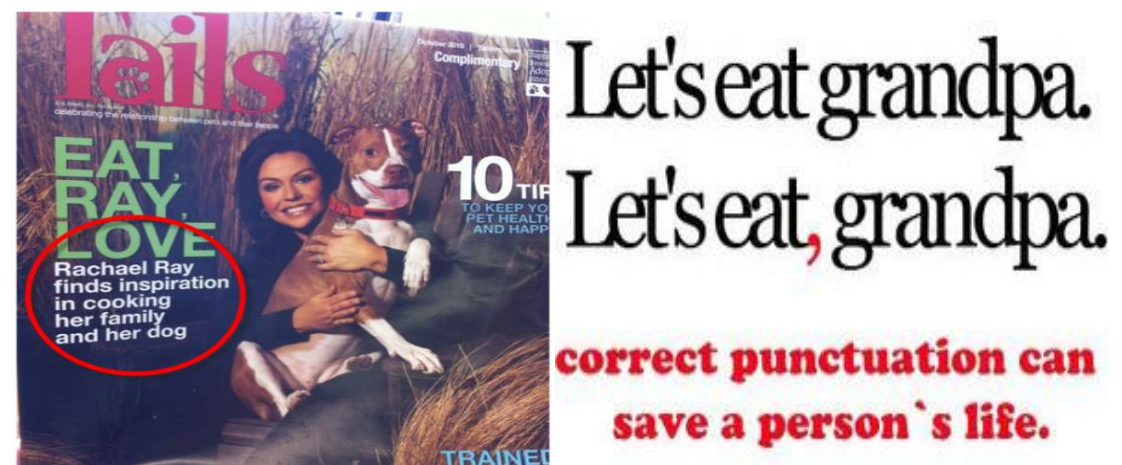

Figure 9. Examples of how "pronunciation can save lives" (idea obtained from: http://cybertext.wordpress.com/2012/11/22/a-light-hearted-look-athow-punctuation-can-change-meaning/) 
14. Identifying sentence focus: a student reads aloud a series of sentences emphasising a different word each time, that is to say, changing the focus of the sentence in each case. The other the students have to identify where the focus is in each case. For example:

I can't believe she told you this!

I can't believe she told you this!

I can't believe she told you this!

I can't believe she told you this!

I can't believe she told you this!

15. Poetry reading: students have to choose a poem they particularly like and recite it in class. At the end, students will choose their favorite poetry and the best performance. This can also be done with short theatre fragments or with other texts from different genres.

Obviously, all these activities admit and benefit from introducing new aspects or adaptations. Teachers have to feel free to introduce any variable or modification they consider necessary according to their students' needs since innovation is a key aspect in order to keep students' interest.

\section{CONCLUSION}

The role of English as the lingua franca nowadays makes it especially relevant the fact of being able to successfully communicate in English. This communication depends on the fact that mutual intelligibility or comprehensibility exists, and pronunciation is crucial in this respect.

From the different aspects analysed throughout this paper and from the results obtained in its corresponding research, it seems relevant to note that -despite the added difficulty arisen from the fact that a second or foreign language is normally learnt in an artificial environment- pronunciation can be taught and learnt with a wide variety of methods and activities that make students naturally and confidently improve and progress.

According to the results obtained students are motivated and seem to acknowledge the importance of pronouncing properly since, otherwise, comprehensibility would be affected and thus communication broken. Affective factors as well as a positive, reinforcing classroom atmosphere do also play a key role in pronunciation instruction. Realistically setting goals and reflecting about the feasibility of sounding "absolutely native" is an important aspect to develop and consider in pronunciation classes in order to avoid unnecessary frustration. In the same way, it is important to show positive reinforcement to those students with weaker capabilities since it is frustrating for most of them to see how some classmates have much better pronunciation than them.

As research shows, students emphasise the importance of using audiovisual means to foster imitation patterns and are aware of the importance of becoming familiar with both segmental and suprasegmental aspects. Students like variation in class activities as well as being provided with real and natural language models to imitate (together with the more traditional didactic approach offered by the coursebook). They do also need fun activities which help them to more naturally deal with pronunciation issues, helping them to forget a bit about the stress of consciously or unconsciously being subject to evaluation on the part of their peers and the teacher. In this way, students appreciate the effort devoted by teachers in order to devise activities specifically addressed to the particular needs detected in class. This involvement on the part of the teacher makes them feel more confident and valued and this positively affects their attitude to the subject and to the skill under development.

What seems clear is that students have a lot to say in their learning process; they reflect on what is good for them more than we may think at first sight and asking them is the best way to incorporate their suggestions and perceptions to our teaching and thus to their learning. Questionnaires such as the ones employed in this study can shed light on the way students want or need to be taught and even on aspects traditionally problematic or a bit abandoned.

From the results obtained it seem obvious that in a pronunciation class it is fundamental that students feel comfortable, encouraged to improve and motivated, never pushing them beyond their own will, otherwise, group or class work will negatively affect the student's learning process and eagerness instead of fostering intelligibility for use beyond the classroom.

APPENDiX A. QUESTIONNAIRES

\section{QUESTIONNAIRE 1 - STUDENTS' PERCEPTIONS AND FEELINGS \\ AGE GENDER}

$1=$ strongly disagree $\quad 2=$ disagree $\quad 3=$ indecisive $\quad 4=$ agree $\quad 5=$ absolutely agree

\begin{tabular}{|ll|l|}
\hline 1. & I am concerned about my pronunciation. & \\
\hline 2. & I consider "English comprehension and pronunciation" an important subject in my degree. & \\
\hline 3. & I think "English comprehension and pronunciation" will help me to improve my pronunciation. & \\
\hline 4. & I consider pronunciation a key aspect for communication. & \\
\hline 5. & I think English pronunciation is important for my professional future. & \\
\hline 6. & I can see the relevance of most of what we are taught in this subject. & \\
\hline 7. & I like learning English pronunciation. & \\
\hline 8. & I enjoy my English pronunciation lessons/classes. & \\
\hline
\end{tabular}




\begin{tabular}{|ll|l|}
\hline 9. & I enjoy participating in games and tasks in the English pronunciation class. & \\
\hline 10. & I feel insecure when I have to speak in English in front of my classmates. & \\
\hline $\begin{array}{l}11 . \\
\text { insecure so I deliberately avoid sounding too native-like. }\end{array}$ & I could do much better when I speak in English in front of my classmates but I feel ashamed and \\
\hline 12. & I want to be able to pronounce English just like native speakers. & \\
\hline 13. & It is very frustrating not be able to sound as an English native. & \\
\hline 14. & I am satisfied with my pronunciation in English. & \\
\hline 15. & If I have a good pronunciation, then I will feel more confident in English. & \\
\hline 16. & Pronunciation skills are innate. & \\
\hline 17. & Pronunciation skills are acquired through practice. & \\
\hline 18. & I think my mother tongue is a handicap for pronouncing more correctly. & \\
\hline $\begin{array}{l}19 . \\
\text { pronunciation. }\end{array}$ & Knowing the main theoretical aspects of phonetics and phonology does not ensure a good \\
\hline 20. & I am satisfied with the effort I devote to improve my pronunciation. & \\
\hline 21. & It is frustrating to see how some classmates have much better pronunciation than me. & \\
\hline 22. & I feel that learning English pronunciation correctly is too difficult for me. \\
\hline 23. & Speaking is the hardest skill to develop. \\
\hline 24. & I think I will never feel satisfied with my pronunciation. & \\
\hline 25. & I feel nervous in my English pronunciation class. \\
\hline
\end{tabular}

\section{QUESTIONNAIRE 2 - MATERIALS, METHODS, TOOLS AND CONTENTS EMPLOYED \\ AGE GENDER

$1=$ strongly disagree $\quad 2=$ disagree $\quad 3=$ indecisive $\quad 4=$ agree $\quad 5=$ absolutely agree

\begin{tabular}{|c|c|c|}
\hline 1. & I think pronunciation symbols are useful for learning pronunciation correctly. & \\
\hline 2. & I think English textbooks can help me to learn English pronunciation. & \\
\hline 3. & I think English videos and audios can help me to learn English pronunciation. & \\
\hline 4. & I think that singing songs in English can improve my pronunciation. & \\
\hline 5. & I think that repetition and imitation are important aspects to learn English pronunciation. & \\
\hline 6. & I think that recording myself is useful to improve my pronunciation. & \\
\hline 7. & The use of printed dictionaries is important for learning pronunciation. & \\
\hline 8. & The use of online dictionaries is important for learning pronunciation. & \\
\hline 9. & Students should be given more chances to speak in class. & \\
\hline 10. & Attending classroom activities is helpful. & \\
\hline 11. & The language lab is useful for pronunciation classes. & \\
\hline 12. & Intonation is an important aspect in order to master English pronunciation. & \\
\hline 13. & Intonation is a difficult aspect to learn. & \\
\hline 14. & Word and sentence stress is an important aspect in order to master English pronunciation. & \\
\hline 15. & Word and sentence tress is a difficult aspect to learn. & \\
\hline 16. & Correct mouth articulation is an important aspect in order to master English pronunciation. & \\
\hline 17. & Correct mouth articulation is a difficult aspect to learn. & \\
\hline \multicolumn{2}{|r|}{$\begin{array}{l}\text { 18. Consonant sounds (voiced and unvoiced) are an important aspect in order to master English } \\
\text { pronunciation. }\end{array}$} & \\
\hline 19. & Consonant sounds (voiced and unvoiced) are a difficult aspect to learn. & \\
\hline \multicolumn{2}{|r|}{$\begin{array}{l}20 . \quad \text { Vowel sounds (single (short and long) and diphthongs) are an important aspect in order to master } \\
\text { English pronunciation. }\end{array}$} & \\
\hline 21. & Vowel sounds (single (short and long) and diphthongs) are a difficult aspect to learn. & \\
\hline 22. & I find phonetic transcription "reading" exercises useful. & \\
\hline 23. & I find phonetic transcription "writing" exercises useful. & \\
\hline 24. & I find minimal pairs exercises useful. & \\
\hline 25. & I find tongue twisters exercises useful. & \\
\hline 26. & I find written coursebook exercises useful. & \\
\hline 27. & I find listening coursebook exercises useful. & \\
\hline 28. & I find pronunciation lists useful. & \\
\hline 29. & I find reading aloud exercises useful. & \\
\hline 30. & I find dialogue enacting exercises useful. & \\
\hline
\end{tabular}

\section{QUESTIONNAIRE 3 - WORK NEEDED, PERCEIVED RELEVANCE AND IMPROVEMENT SUGGESTIONS \\ AGE \\ GENDER}

\section{IMPROVEMENT SUGGESTIONS}

1. What are the specific aspects you specially need to work on? (order them from 1 (more work needed) to 8 (less work needed)

Consonant sounds

Vowel sounds

Connected speech

Phonetic transcription production

Phonetic transcription reading

Mouth articulation 
Stress

Intonation

2. How important do you consider the following pronunciation-related aspects to be? (from $1=$ not at all to $5=\mathrm{a}$ lot)

Consonant sounds

Vowel sounds

Connected speech

Phonetic transcription production

Phonetic transcription reading

Mouth articulation

Stress

Intonation

3. How would you improve classroom activities?

4. How would you improve students' participation?

5. How would you improve teacher's methodology?

6. How would you improve materials?

7. How would you particularly improve your classmates' pronunciation skills?

8. What specific types of activities would you suggest for improving your pronunciation?

9. Why is pronunciation such a hard issue (in general) for Spanish students?

10. Is there anything you would like to do in class (in order to improve your pronunciation) that has never been done before?

\section{REFERENCES}

[1] Akram, M. and Qureshi, A. H. (2012). Problems in Learning and Teaching English Pronunciation in Pakistan. International Journal of Research in Linguistics and Lexicography. INTJR-LL-1(4), 43-48.

[2] Burns, A. (2003). Clearly speaking: pronunciation in action for teachers. National Center for English Language Teaching and Research, Macquaire Universaity, Sydney NSW 2109.

[3] Coe, N. (1987) in Swan, M. \& Smith, B. Learner English: A teacher's guide to interference and other problems. Cambridge University Press.

[4] Case, A. (2012). http://edition.tefl.net/articles/teacher-technique/spanish-speaker-pronunciation-problems/ (accessed 1/07/2013).

[5] Cunningham Florez, M. (1998). Improving Adult ESL Learners' Pronunciation Skills. ERIC Digest.

[6] Hancock, M. (2003). English Pronunciation in Use. Intermediate. Cambridge: Cambridge University Press (course book).

[7] Howlader, M. R. (2010). Teaching English Pronunciation in Countries where English is a Second Language: Bangladesh Perspective. ASA University Review 4. 2, 233-244.

[8] Jones, R. H. (2002). Beyond listen and repeat: Pronunciation teaching materials and theories of second language acquisition. In J. C. Richards \& W. A. Renandya, Methodology in language teaching: An anthology of current practice. Cambridge: Cambridge University Press, 12-16.

[9] Kang, O. (2010). ESL learners' attitudes toward pronunciation instruction and varieties of English. In J. Levis \& K. LeVelle (eds.), Proceedings of the 1st Pronunciation in Second Language Learning and Teaching Conference. Ames, IA: Iowa State University, 105-118.

[10] Moyer, A. (2004). Age, accent and experience in second language acquisition. Clevedon, England: Multilingual Matters.

[11] Odlin, T. (1989). Language transfer: Cross-linguistic influence in language learning. Cambridge: Cambridge University Press.

[12] Pourhosein Gilakjani, A. (2012). A Study of Factors Affecting EFL Learners' English Pronunciation Learning and the Strategies for Instruction. International Journal of Humanities and Social Science 2. 3, 119-128.

[13] Scovel, T. (2000). A critical review of the critical period research. Annual Review of Applied Linguistics, 20, $213-223$.

[14] Shoebottom, P. (2011). http://esl.fis.edu/grammar/langdiff/spanish.htm (accessed 1/07/2013).

[15] Ur, P. (1996). A course in language teaching: practice and theory. Cambridge; New York: Cambridge University Press.

Nuria Edo Marzá was born in Spain in 1980. She received her PhD in English Philology from University Jaume I (Castellón, Spain) in 2008. She also received a master's degree in Terminology in 2009 from Universitat Pompeu Fabra (Barcelona, Spain). She is currently a professor of the English Studies Department at Universitat Jaume I (Castellón, Spain) but she also worked as a lecturer and researcher from 2009 to 2011 at University of Valencia (Spain).

She is the author of the book The Specialised Lexicographical Approach: a Step Further in Specialised Dictionary Making (2009) Peter Lang, and of the health-related volumes Spoken English for the medical professional (2011), English for Patient and nonclinical Hospital Staff (2011) and English for Pharmacists (2011), all of them published by Editorial Formación Alcalá. She is also the author of the research paper "The generation of active entries in a specialised, bilingual, corpus-based dictionary of the ceramics industry: what to include, why and how" (2009). Ibérica, 18, 43-71.

Dr. Edo research interests include the fields of specialised languages, terminology, terminotics, specialised lexicography and ESP teaching and learning among others. 